\title{
Sutureless coronary anastomosis with an anastomotic device and tissue adhesive in off-pump porcine coronary bypass grafting
}

\author{
Marc P. Buijsrogge, $M D^{a}$ \\ Jules S. Scheltes, MSc ${ }^{\mathrm{b}}$ \\ Martijn Heikens, $\mathrm{BSc}^{\mathrm{b}}$ \\ Paul F. Gründeman, MD, $\mathrm{PhD}^{\mathrm{a}}$ \\ Peter V. Pistecky, MSc ${ }^{b}$ \\ Cornelius Borst, MD, PhD
}

From the Heart Lung Center Utrecht, University Medical Center Utrecht, Utrecht, ${ }^{\mathrm{a}}$ and Department of Design, Engineering and Production, Delft University of Technology, Delft, ${ }^{\text {, }}$ The Netherlands.

J.S.S., M.H., and this research were supported by the Technology Foundation STW (grant UGN 66.4183), the applied science division of the Netherlands Organization for Scientific Research, and the Technology Program of the Ministry of Economic Affairs.

Received for publication June 7, 2001; revisions requested Aug 1, 2001; revisions received Aug 29, 2001; accepted for publication Sept 10, 2001

Address for reprints: Cornelius Borst, MD, $\mathrm{PhD}$, Professor of Experimental Cardiology, University Medical Center Utrecht (Room G02.523), Heart Lung Center Utrecht, PO Box 85500, 3508 GA Utrecht, The Netherlands (E-mail: c.borst@hli.azu.nl).

J Thorac Cardiovasc Surg 2002;123:788-94

Copyright ( $(2) 2002$ by The American Association for Thoracic Surgery

0022-5223/2002 \$35.00+0 $\quad \mathbf{1 2 / 1 / 1 2 0 3 3 6}$

doi: $10.1067 / \mathrm{mtc} .2002 .120336$
Objective: In the search for a facilitated coronary artery anastomosis, we assessed the feasibility of a hybrid anastomosis technique that used a prototype anastomotic device with an extraluminal frame (crinoline-like) and octyl-cyanoacrylate adhesive.

Methods: During off-pump coronary artery bypass grafting in pigs $(\mathrm{n}=8)$, a left internal thoracic artery-right coronary artery anastomosis was constructed and evaluated during the operation and at 5 postoperative weeks. The anastomosis was examined by flow measurement, angiography, intraluminal cast geometric analysis, and histologic analysis.

Results: Anastomosis construction required $6.2 \pm 1.3$ minutes (mean $\pm \mathrm{SD}$ ). At 5 weeks all anastomoses were fully patent, with minor anastomotic diameter narrowing (median 16\%, 15th-85th percentile 16\%-26\%). After 30-second graft occlusion, median peak hyperemic flow response was 5.0 (15th-85th percentile 4.4-6.5). As a result of complete, streamlining filling of anastomotic wall recesses by neointima formation, more intimal hyperplasia was found in the crinoline-adhesive anastomoses than in sutured control anastomoses. No excessive, lumen-narrowing neointima formation was observed, however.

Conclusions: The hybrid coronary anastomosis technique was feasible without any need for dedicated application tools. If technical improvements can be realized, the hybrid technique may provide an alternative to manual suturing.

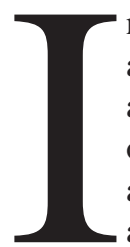

$\mathrm{n}$ the search for a facilitated coronary artery anastomosis, ${ }^{1,2}$ we developed a hybrid anastomosis technique that combines mechanical coupling and adhesive bonding without any need for dedicated application tools. Our objective was to assess the feasibility of this technique with a prototype anastomotic device with extraluminal frame (due to crinoline-like appearance called the crinoline; Figure 1,A) and octyl-cyanoacrylate tissue adhesive during off-pump porcine left internal thoracic artery (ITA) to right coronary artery (RCA) bypass grafting. We subsequently investigated anastomotic patency, intraluminal geometry, and histomorphologic aspects of vascular wall healing at 5 postoperative weeks.

\section{Material and Methods}

\section{Animals}

Eight Dutch female landrace pigs (weighing 70-90 kg) were used. The animals were fed a normal diet and received humane care in compliance with the Guide for the Care and Use of Laboratory Animals prepared by the Institute of Laboratory Animal Resources, National 


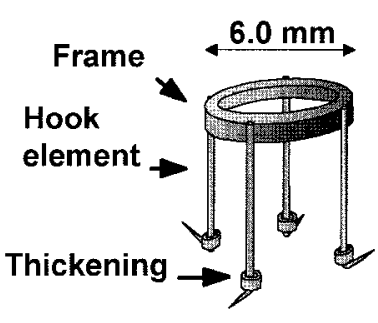

A

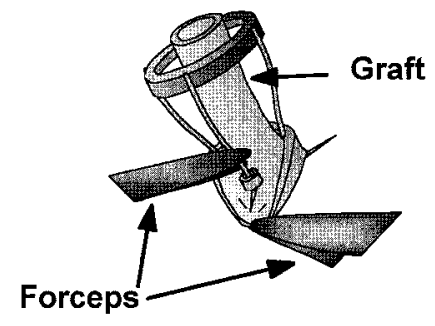

$\mathbf{B}$

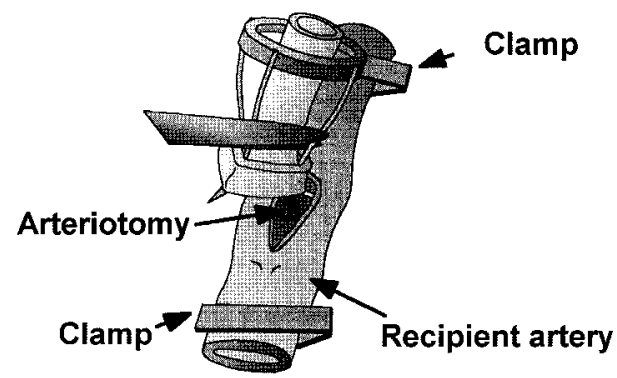

C

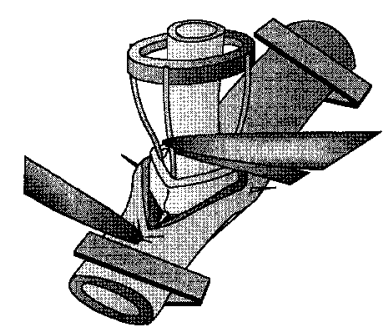

D

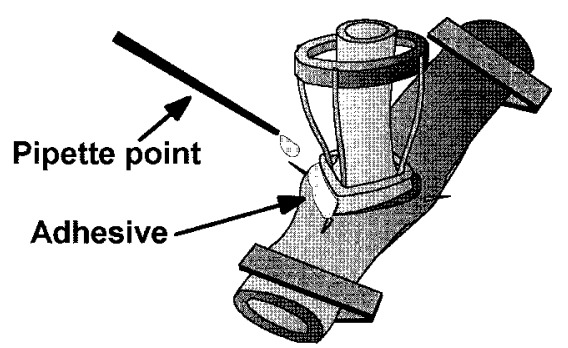

E

Figure 1. Crinoline-adhesive anastomotic procedure. A, Crinoline-like bonding device consists of stainless steel ring-shaped frame (outside diameter $6.0 \mathrm{~mm}$ ) and four downward axially extending hook elements (length $8.0 \mathrm{~mm}$ ) with thickenings at end. Hook elements are elastically bendable. B, End of graft, cut at $90^{\circ}$ angle, is passed through orifice of ring, everted, and impaled over hook elements, which results in slight lumen area reduction. Thickenings near tip of elements prevent graft from sliding upward. C and D, Mounted crinoline is hooked in coronary artery in intima-intima apposition of graft and recipient artery. $E$, In response to radially directed forces of the elements, anastomotic line of end-to-side anastomosis is slightly stretched, after which fixed apposition is consolidated by adhesive.

Research Council, and published by the National Academy Press, revised 1996. The protocol was approved by the animal experimentation committee of the Utrecht University. All animals received $560 \mathrm{mg}$ acetylsalicylic acid orally 1 day before the operation. This was continued at a dose of $160 \mathrm{mg} / \mathrm{d}$ until the animals were killed.

\section{Anesthesia and Analgesia}

Anesthesia was induced by intramuscular injection of ketamine $(10 \mathrm{mg} / \mathrm{kg})$ and intravenous injections of thiopental sodium (4 $\mathrm{mg} / \mathrm{kg}$ ), atropine $(1 \mathrm{mg}$ ), and the antibiotic amoxicillin (INN: amoxicilline; $500 \mathrm{mg}$ ). A mixture of oxygen and air (1:1 volume/ volume) with $0.5 \%$ to $1 \%$ halothane was administered, along with intravenously administered midazolam $(0.3 \mathrm{mg} /[\mathrm{kg} \cdot \mathrm{h}])$ and propranolol (range $10-25 \mathrm{mg}$ ). Analgesia was obtained by sufentanil citrate $(1 \mu \mathrm{g} /[\mathrm{kg} \cdot \mathrm{h}])$ and muscle relaxation by pancuronium $(0.1$ $\mathrm{mg} /[\mathrm{kg} \cdot \mathrm{h}])$. For 3 days after the operation, amoxicillin trihydrate $(15 \mathrm{mg} / \mathrm{kg})$ and buprenorphine $(0.6 \mathrm{mg})$ were administered intramuscularly to provide analgesia.

\section{Euthanasia}

Pentobarbital sodium $(200 \mathrm{mg} / \mathrm{kg}$ ) was given intravenously after sufficient heparin had been administered to obtain an activated clotting time (Medtronic HemoTec, Inc, Englewood, Colo) of at least 4 times the control value. 


\begin{abstract}
Surgery
After a partial median sternotomy, the left ITA was harvested in a skeletonized fashion. After intravenous administration of heparin (not counteracted at the end of the procedure) to obtain an activated clotting time (determined at $0,10,60,90$ minutes after injection, and so on until the end of the procedure) of twice the control value, the distal left ITA was dissected and sprayed with a papaverine-saline solution $(5 \mathrm{mg} / \mathrm{mL})$ to prevent spasm. The vessel half circumference was measured with a caliper. The pericardium was opened, and the right side was suspended by deep pericardial sutures to expose the RCA, which was immobilized by the Octopus 2 Tissue Stabilizer (Medtronic, Inc, Minneapolis, Minn). Loose periadventitial tissue was removed, and the outer vessel diameter was measured.
\end{abstract}

\section{Anastomotic Procedure}

Under the microscope (magnification 6.25; Wild M680; Leica AG, Heerburg, Switzerland), the distal end of the left ITA was cut at an angle of about $90^{\circ}$, mounted on the crinoline device (Figure 1, B), and irrigated with saline solution to avoid dehydration. Coronary preconditioning was achieved by 5 minutes of stop-flow ischemia with a microvascular Acland clamp (B-3V; S\&T Marketing Ltd, Neuhausen, Switzerland) and 5 minutes of reperfusion. After reclamping, a longitudinal slit arteriotomy with a length of half the left ITA circumference was performed with a diamond knife. Two crinoline hook elements, at 3 and 9 o'clock positions relative to the anastomosis, were inserted individually into the coronary artery wall with a conventional forceps (Figure 1,C); this application was followed by the heel and toe hook elements (Figure 1, D).

After the vessel wall was scrutinized for proper coaptation, an air blower (ClearView Blower/Mister; Medtronic) removed moisture before adhesive application. About $0.3 \mu \mathrm{L}$ octyl-cyanoacrylate adhesive (Dermabond; Ethicon, Inc, Somerville, NJ) taken from $-4^{\circ} \mathrm{C}$ freezer storage was applied over the anastomotic line between the hook elements (Figure 1, E) with a pipette (Proline Pipette; Biohit OY, Helsinki, Finland) and pipette point (200 $\mu \mathrm{L}$; Greiner GmbH, Frickenhausen, Germany). After adhesive polymerization, left ITA graft flow was restored and the RCA proximal to the end-to-side anastomosis was occluded with two medium Atraumaclips (Pilling, Inc, Fort Washington, Pa). The left ITA was tagged to the epicardium to prevent traction on and kinking of the graft.

All animals were evaluated during and 5 weeks after the operation. Recently performed conventionally sutured left and right ITA-LAD anastomoses from a comparable series of experiments ${ }^{3}$ were analyzed identically and served as control groups for operative parameters $(n=28)$, intraoperative and postoperative measurements, angiography, and histologic examination $(\mathrm{n}=18)$.

\section{Intraoperative and Postoperative Measurements}

After completion of the anastomosis and stabilization of flow, mean ITA flow was recorded with a calibrated transit time flow probe (3S model T208; Transonic Systems, Inc, Ithaca, NY) at a mean blood pressure of $90 \mathrm{~mm} \mathrm{Hg}$. After ITA clamping for 30 seconds, the coronary peak hyperemic response was determined (in duplicate at an interval of at least 10 minutes) as the peak mean graft flow divided by the mean baseline flow at $90 \mathrm{~mm} \mathrm{Hg}$, both after anastomosis construction and at 5 postoperative weeks. Before chest closure, ITA flow was monitored continuously for as long as 2 hours.

\section{Angiography}

After the animals were killed at 5 postoperative weeks, the anastomoses were visualized by left ITA angiography (C-arm BV27; Philips, Eindhoven, The Netherlands) at about $80 \mathrm{~mm} \mathrm{Hg}$ and graded by an independent observer according to the method of Fitzgibbon and colleagues. ${ }^{4}$

\section{Intraluminal Geometry Analysis}

After angiography, the heart was perfused for 30 seconds with a papaverine-saline solution $(5 \mathrm{mg} / \mathrm{mL})$ and for 30 minutes with $4 \%$ formalin at $80 \mathrm{~mm} \mathrm{Hg}$ with a low perfusion rate. The arteries were filled with liquid hardening silicone material (polyvinylsiloxane impression material type 3; Kerr, Romulus, Mich) under a low pressure and perfusion rate. The anastomotic segments were excised, and the hardened silicone cast was removed through a longitudinal incision in the floor of the coronary artery. The cast material was cut in transverse planes (smallest cross-sectional area of anastomotic orifice, graft at ring frame, distal coronary outflow, and the graft and coronary artery area at $4-5 \mathrm{~mm}$ and $8-10 \mathrm{~mm}$ from anastomotic orifice [reference segments], respectively). The areas were digitized and measured with software package AnalySiS (Soft-Imaging Software GmbH, Münster, Germany).

\section{Histologic Analysis}

After removal of cast material, the crinoline device in the anastomotic segment was removed. After overnight fixation in formalin $4 \%$, the anastomotic segments (plus ITA segment at ring frame and two [proximal RCA and left ITA] reference segments) were embedded in paraffin. One half of the anastomosis and the left ITA ring frame segment were sectioned in the longitudinal plane; the other half and reference segments in the transverse plane (3 adjacent midline sections at roughly $100-\mu \mathrm{m}$ intervals). The sections were stained with hematoxylin and eosin, van Gieson elastin, and Oil Red O stain (Merck KGaA, Darmstadt, Germany), the last to stain the adhesive. In van Gieson elastin-stained sections, the area enclosed by the luminal border and internal elastic laminae adjacent to the anastomotic line was measured in square millimeters and defined as intimal hyperplasia (at toe, heel, and lateral walls of the anastomoses).

\section{Statistical Analysis}

Data are presented as mean \pm SD or as median and 15 th through 85 th percentiles. Repeated measures analysis of variance by general linear model was used to compare means through the use of the SPSS software package (SPSS, Inc, Chicago, Ill), and the Bonferroni correction was used to adjust for multiple comparisons.

\section{Results}

Surgery

The anastomoses were performed by a single investigator (M.P.B.). The operative data are given in Table 1. Mounting of the left ITA on the crinoline required $3.2 \pm 0.9$ minutes. 
TABLE 1. Operative data

\begin{tabular}{lcrr}
\hline & & \multicolumn{1}{c}{ Control } & \multicolumn{1}{c}{ Low flow* } \\
\cline { 2 - 4 } & Crinoline-adhesive & High flow* & $8.9 \pm 1.5$ \\
Anastomosis surgery time (min) & $6.2 \pm 1.3$ & $9.3 \pm 1.7$ & $10.0 \pm 1.7$ \\
Coronary occlusion time (min) & $7.2 \pm 1.2$ & $10.4 \pm 2.1$ & $3.5 \pm 0.0$ \\
Arteriotomy length (mm) & $3.2 \pm 0.4$ & $3.6 \pm 0.2$ & $2.1 \pm 0.2$ \\
Graft outer diameter (mm) & $2.2 \pm 0.3$ & $2.4 \pm 0.4$ & $2.8 \pm 0.4$ \\
Coronary outer diameter $(\mathrm{mm})$ & $4.2 \pm 0.3$ & $3.3 \pm 0.5$ & \\
\hline
\end{tabular}

Data are presented as mean \pm SD.

${ }^{*}$ Sutured anastomoses (ITA-left anterior descending coronary artery, $n=14$ ) from a previous study. ${ }^{3}$

TABLE 2. Intraoperative and postoperative measurements

\begin{tabular}{|c|c|c|c|}
\hline & \multirow[b]{2}{*}{ Crinoline-adhesive } & \multicolumn{2}{|c|}{ Control } \\
\hline & & High flow* & Low flow* \\
\hline \multicolumn{4}{|c|}{ ITA graft flow $(\mathrm{mL} / \mathrm{min}$, mean $\pm \mathrm{SD})$} \\
\hline Intraoperative & $23 \pm 5$ & $57 \pm 8$ & $10 \pm 3$ \\
\hline $2 \mathrm{~h}$ & $21 \pm 5$ & $74 \pm 19$ & $12 \pm 4$ \\
\hline 5 wk & $28 \pm 6$ & $57 \pm 10$ & $14 \pm 8$ \\
\hline \multicolumn{4}{|c|}{$\begin{array}{l}\text { Coronary peak hyperemic response } \\
\text { (median and 15th-85th percentile) } \dagger\end{array}$} \\
\hline Intraoperative & $4.9(4.4-6.2)$ & $3.2(2.9-3.4)$ & $6.2(4.8-6.8)$ \\
\hline 5 wk & $5.0(4.4-6.5)$ & $4.4(3.0-5.0)$ & $3.4(2.1-6.7)$ \\
\hline
\end{tabular}

Intraoperative measurements made after stabilization of flow after completion of anastomosis. Crinoline-adhesive anastomoses 2 hours versus 5 weeks $P=.045 ;$ overall effect follow-up $P=.007$.

${ }^{*}$ Sutured anastomoses (ITA-left anterior descending coronary artery, $n=9$ ) from a previous study. ${ }^{3}$

tMean of duplicate measurements.

The arteriotomy required $0.9 \pm 0.4$ minutes. Insertion of the crinoline hook elements in the coronary vessel wall required $1.9 \pm 0.8$ minutes. One insertion lasted 6.2 minutes because of multiple reinsertions of hook elements necessitated by vessel wall malalignment. After retrospective analysis, a length discrepancy of one hook element from an assembly error was observed, and the associated time measurement was discarded. Adhesive application (including drying of vessel wall, adhesive application, and polymerization) required $2.4 \pm 0.5$ minutes.

Immediate complete hemostasis was obtained in 5 of 8 crinoline-adhesive anastomoses, compared with 22 of 28 conventionally sutured anastomoses. In 2 cases the initial oozing stopped after 1 minute (similarly to 2 of the conventional anastomoses). In 1 case, the left ITA had to be clamped again after 6 minutes for reapplication of a small amount of adhesive at one anastomotic quadrant, after which complete hemostasis was obtained. Four conventional anastomoses required an additional stitch (without reclamping of the ITA) to obtain complete hemostasis.

The activated clotting times at 0 minutes, during the anastomotic procedure, and at 210 minutes after heparinization were $105 \pm 8,256 \pm 52$, and $147 \pm 30$ seconds, respectively.

\section{Follow-up}

The scheduled 5-week follow-up was completed for all 8 animals, and their weights had increased from $79 \pm 7 \mathrm{~kg}$ to $83 \pm 4 \mathrm{~kg}$.

\section{Intraoperative and Postoperative Measurements}

ITA flow measurements are given in Table 2. No cyclic flow reductions were observed during 2 hours of flow monitoring after anastomosis construction.

\section{Angiography}

When the animals were killed, all anastomoses were fully patent (grade A) without aneurysm formation (Figure 2). Four anastomoses demonstrated anastomotic diameter narrowing of $20 \%$ to $30 \%$. Seventeen of 18 conventional anastomoses were fully patent (grade A) without diameter narrowing; 1 was occluded. In 1 experimental animal, the graft at the level of the ring frame was slightly pinched.

\section{Intraluminal Geometry Analysis}

Angiographic results were confirmed by intraluminal geometry analysis (Table 3). The distal coronary outflow showed expansive artery remodeling. 


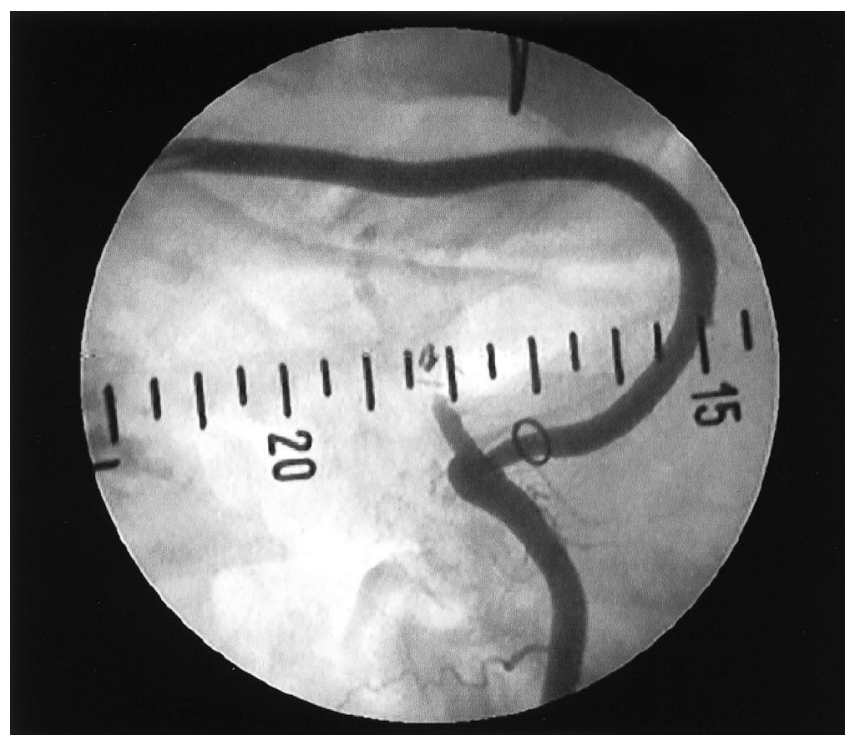

Figure 2. Representative angiogram at 5 postoperative weeks. Note external ring frame of prototype crinoline mechanical coupler.

\section{Histologic Analysis}

Vessel wall apposition. In 6 of 8 anastomoses, complete intima-intima apposition was established along the full circumference. Complete apposition was seen in 13 of 18 conventional anastomoses. In 2 cases a small part of the graft rim at either the heel or the toe of the anastomosis had been exposed to blood. In 5 conventionally sutured anastomoses a small part of either graft or coronary media was exposed to blood. In all crinoline-adhesive anastomoses, at least part of the hook elements at heel or toe (none at lateral walls) had been exposed to blood. No vessel wall dehiscence was observed.

Intimal hyperplasia. Streamlining intimal hyperplasia coverage of the hook elements was found, together with complete filling of anastomotic recesses between everted graft and coronary artery (Figure 3): median $0.81 \mathrm{~mm}^{2}$ (15th-85th percentile $0.69-1.10 \mathrm{~mm}^{2}$ ) at the heel, median $1.10 \mathrm{~mm}^{2}$ (15th-85th percentile $0.88-1.30 \mathrm{~mm}^{2}$ ) at the toe, and median $0.51 \mathrm{~mm}^{2}$ (15th-85th percentile $0.34-0.76$ $\mathrm{mm}^{2}$ ) at the lateral wall, versus median $0.04 \mathrm{~mm}^{2}$ (15th85th percentile $0.03-0.07 \mathrm{~mm}^{2}$ ) and median $0.03 \mathrm{~mm}^{2}$ (15th-85th percentile $0.01-0.05 \mathrm{~mm}^{2}$ ) at the heel and toe, respectively, of conventional anastomoses. No excessive, lumen-narrowing intimal hyperplasia was found in any of the anastomoses, and no hyperplasia was found at the level of the crinoline frame.

Medial necrosis. Full-thickness medial necrosis was recorded near all penetrating hook elements. No medial necrosis or thinning of either coronary or thoracic artery was observed between the hook elements, near adhesive, or at the frame level.

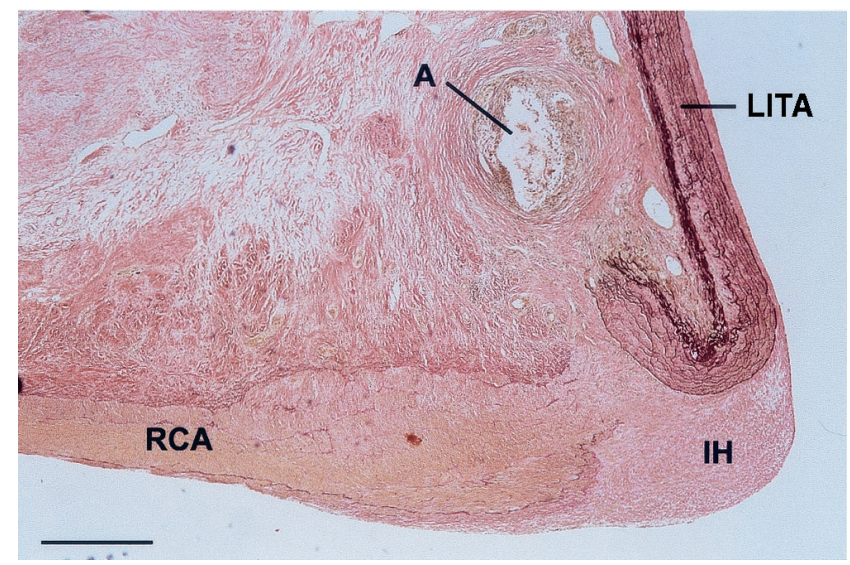

Figure 3. Representative longitudinal histologic section of toe of crinoline-adhesive anastomosis at 5 postoperative weeks, demonstrating streamlining intimal hyperplasia (IH) over anastomotic recess formed by intima-intima apposition. Blank space between adhesive (adhesive void, $\boldsymbol{A}$ ) and graft corresponds to position of hook element after its removal. LITA, Left ITA. Bar represents 250 $\mu \mathrm{m}$. (Elastin van Gieson stain; original magnification $\times 100$.)

Adhesive. At 5 postoperative weeks, little adhesive was found at the application site. No adhesive had been exposed to the blood. Acute inflammatory cell reactions (polymorphonuclear cells) and some chronic inflammatory cell reactions (foreign-body giant cells) were observed only in adventitial vicinity of adhesive or hook elements.

\section{Discussion}

All anastomoses were fully patent (Fitzgibbon grade A) and showed a normal healing response. Despite imperfections in the prototype anastomotic device, the hybrid technique was relatively simple and required $6.2 \pm 1.3$ minutes to complete.

\section{Facilitated Coronary Artery Anastomosis}

Micromechanical fasteners for facilitated anastomoses may be categorized in 3 groups: individual bonding elements (staples, clips, or sutures), ${ }^{2}$ intraluminal frame structures, ${ }^{1}$ and extraluminal frame structures (this study). Extraluminal frame structures are relatively easy to apply and minimize foreign-body exposure to the blood.

To reduce the manual complexity of either conventional suturing or mechanical coupling, we developed a hybrid anastomosis technique that combines extraluminal framebased coupling and adhesive bonding. Four radially expanding elastic hook elements bring the thoracic and coronary artery into proper, fixed apposition, after which the slightly stretched anastomotic quadrants are consolidated with adhesive. Octyl-cyanoacrylate, which is currently approved by the Food and Drug Administration for topical wound closure, was selected because of its strong, fast, and flexible bond and its relatively low histotoxicity. ${ }^{5,6}$ 
TABLE 3. Intraluminal geometry analysis

\begin{tabular}{lccc}
\hline Animal & Ring frame & Anastomotic orifice & Distal outflow RCA \\
\hline 1 & 6 & $28^{*}$ & -40 \\
2 & 11 & 20 & -18 \\
3 & 33 & $24 \dagger$ & -16 \\
4 & 2 & 10 & -12 \\
5 & 10 & $26 \dagger$ & -50 \\
6 & 2 & 10 & -51 \\
7 & 5 & 11 & -34 \\
8 & -1 & 9 & -11 \\
Median & 6 & 16 & -26 \\
15th-85th percentile & $2-11$ & $16-26$ & -49 to -12 \\
\hline
\end{tabular}

Data represent diameter narrowing as a percentage. Diameter narrowing (relative to reference diameter) was calculated as follows: Diameter narrowing $=$ $\left(1-\right.$ diameter $_{\text {site }} /$ diameter $\left._{\text {reference }}\right) \times 100 \%=\left[1-\sqrt{\left(A_{\text {site }} / A_{\text {reference }}\right)}\right] \times 100 \%$.

*Misalignment of hook element thickenings.

tDetachment of hook element.

‡Negative value produced by expansive coronary artery remodeling.

\section{Crinoline-Adhesive Procedure}

With conventional surgical instruments only, insertion of the mounted crinoline into the arteriotomy was easy. A full view of every anastomotic quadrant facilitated proper positioning. In cases of misalignment, repositioning of one or more hook elements required little time.

Similar to acute experiments (not shown), at 5 weeks the method of fixed graft eversion into the coronary artery resulted in minor anastomotic narrowing (median 16\%, 15th-85th percentile 16\%-26\%) without hemodynamic significance (median peak hyperemic flow response 5.0, 15th85th percentile 4.4-6.5). Neither vessel wall stresses resulting from graft eversion, vessel wall stretching by the expanding hook elements, nor the adhesive caused medial necrosis, lumen-constricting wall healing, or intimal hyperplasia. Relative to conventional anastomoses, more intimal hyperplasia was observed; this was attributable to some invagination of the fixed graft into the coronary artery. The resulting circumferential recesses between everted graft and coronary artery were completely filled and reorganized with streamlining intimal hyperplasia; however, no excessive, lumen-narrowing intimal hyperplasia was found in any of the crinoline-adhesive anastomoses. The long-term effects, though, of this hybrid anastomosis technique (histotoxicity and anastomotic quality) remain to be established.

\section{Limitations of the Procedure}

The crinoline-adhesive procedure has limitations. First, at present octyl-cyanoacrylate has been approved for topical wound closure only. Second, graft eversion onto the elements was a delicate maneuver and resulted in slight anastomotic diameter narrowing. In cases of asymmetric hook element placement, correct symmetric graft eversion could only be realized by bending the elements while restraining the ITA. Third, to match anastomotic orifices, the arteriotomy length needs to be half the graft circumference. A mismatched arteriotomy will lead to vessel wall misalignment, with the possibility of insufficient adhesive polymerization or adhesive exposure to the blood. Fourth, the external ring frame is too high, although we did not observe any hemodynamically significant kinking of the ITA graft at the level of the frame.

Provided these limitations can be addressed and anastomosis construction time can be further reduced substantially, we believe that a hybrid anastomosis technique with a micromechanical coupler and adhesive or sealant could provide an alternative to suturing. It remains a matter of speculation whether the crinoline anastomotic device is applicable to human atherosclerotic coronary arteries. We expect the device to function properly when the coronary wall contains plaque and even calcifications.

\section{Conclusions}

A hybrid distal anastomosis technique with a prototype micromechanical coupler and octyl-cyanoacrylate adhesive proved to be feasible for off-pump left ITA-RCA bypass surgery in the pig. Provided technical improvements can be realized that simplify its application and reduce the 6-minute construction time, the hybrid anastomotic technique may provide an alternative to manual suturing.

We acknowledge the constructive contributions of the engineers, J. W. Brinkhof, A. H. M. van Adrichem, and M. Pelle, from DTO-MOP Delft University of Technology, and C. W. J. Verlaan, A. R. T. Donders, PhD, M. H. P. van Rijen, BSc, M. Schurink, S. van der Horst, and colleagues from the Utrecht University Central Animal Facilities. We thank A. Brutel de la Rivière, $\mathrm{MD}, \mathrm{PhD}$, for comments on the manuscript.

\section{References}

1. Eckstein FS, Bonilla LF, Meyer B, Berg TA, Neidhart PP, Schmidli J, et al. Sutureless mechanical anastomosis of a saphenous vein graft to 
a coronary artery with a new connector device. Lancet. 2001;357: 931-2.

2. Heijmen RH, Hincliffe P, Borst C, Verlaan CW, Mouës CM, van der Helm YJ, et al. A novel one-shot anastomotic stapler prototype for coronary artery bypass grafting on the beating heart: feasibility in the pig. J Thorac Cardiovasc Surg. 1999;117:117-25.

3. Buijsrogge MP, Gründeman PF, Verlaan CW, Borst C. Unconventional vessel wall apposition in off-pump porcine coronary bypass grafting: low versus high graft flow. J Thorac Cardiovasc Surg. 2002;123:341-7.
4. Fitzgibbon GM, Kafka HP, Leach AJ. Coronary bypass graft fate and patient outcome: angiographic follow-up of 5,065 grafts related to survival and reoperation in 1,388 patients during 25 years. $J$ Am Coll Cardiol. 1996;28:616-26.

5. Hall WW, Wrye SW, Banducci DR, Ehrlich P. Microvascular anastomosis using 2-octyl-cyanoacrylate in the rat femoral artery. Ann Plast Surg. 2000;44:508-11.

6. Bastiaanse J, Borst C, van der Helm YJ, Loo KH, Gründeman PF. Arteriotomy closure by glued patch in the porcine carotid artery. Ann Thorac Surg. 2000;70:1384-8.

\section{Timely}

The Journal of Thoracic and Cardiovascular Surgery delivers the information you need now. Articles usually appear within four months of acceptance. 